

\begin{tabular}{|c|l|}
\hline Title & $\begin{array}{l}\text { Familial type I hyperlipoproteinemia caused by } \\
\text { apolipoprotein C-II deficiency }\end{array}$ \\
\hline Author(s) & Yamamura, Taku \\
\hline Citation & \\
\hline Issue Date & \\
\hline oaire:version & VoR \\
\hline URL & https://hdl. handle. net/11094/32883 \\
\hline rights & \\
\hline Note & \\
\hline
\end{tabular}

Osaka University Knowledge Archive : OUKA

https://ir. Library. osaka-u. ac. jp/

Osaka University 
Atherosclerosis, 34 (1979) 53-65

(C) Elsevier/North-Holland Scientific Publishers, Ltd.

\title{
FAMILIAL TYPE I HYPERLIPOPROTEINEMIA CAUSED BY APOLIPOPROTEIN C-II DEFICIENCY
}

\author{
TAKU YAMAMURA *, HIROSHI SUDO, KATSUNORI ISHIKAWA and \\ AKIRA YAMAMOTO **
}

Second Department of Internal Medicine, Osaka University Medical School and

** Department of Pathological Science, Research Institute, National Cardiovascular Center, Osaka (Japan)

(Received 30 April, 1979)

(Revised, received 8 May, 1979)

(Accepted 18 June, 1979)

\section{Summary}

A study was made on the clinical and biochemical features of siblings of patients with hyperchylomicronemia and its inherited relationship. It was not a case of the classical type of familial LPL deficiency, but of familial apolipoprotein C-II deficiency. The first patient with apolipoprotein C-II deficiency was reported by Breckenridge et al. and our patients provide the basis for the second report of this new disease. Our observations in this study strongly suggest that familial apolipoprotein C-II deficiency is transmitted by an autosomal recessive mode of inheritance and heterozygotes of this disorder have no abnormalities of plasma lipid and lipoproteins in spite of the reduced plasma apolipoprotein C-II.

Key words: Apolipoproteins - Chylomicrons - Familial hyperlipoproteinemia - Genetic disease - Lipoprotein lipase - Lipoproteins

\section{Introduction}

Familial type I hyperlipoproteinemia is a rare disease characterized by an extreme increase of chylomicrons in the serum [1]. The biochemical defect of this disease has been thought to be an impaired clearance of chylomicrons because of deficiency of lipoprotein lipase (LPL) which catalyzes the hydrolysis of triglyceride-rich lipoproteins $[1,2]$. LPL localizes on the surface of

\footnotetext{
* Present address: The Department of Pathological Science, Research Institute, National Cardiovascular Center, 5-125, Fujishiro-dai, Suita-shi, Osaka-fu, 565 Japan.
} 
capillary endothelium and requires a cofactor for its activity, apolipoprotein C-II [3-6], which is present in serum. The enzyme is released into plasma by intravenous injection of heparin. Postheparin plasma also contains another lipolytic enzyme, hepatic triglyceride lipase (H-TGL) [7,8], but only LPL activity is usually deficient in postheparin plasma from patients with familial type I hyperlipoproteinemia [9].

Recently, Breckenridge et al. [10] reported a patient with hypertriglyceridemia associated with deficiency of apolipoprotein C-II. The patient, a 59year-old male, had clinical and biochemical features similar to type I hyperlipoproteinemia and apparently had LPL deficiency. In his own postheparin plasma, however, LPL was actually present, and only an activator for it - apo C-II - was absent.

In this paper, we describe two cases (a brother and a sister) of familial hyperchylomicronemia caused by apo C-II deficiency; the second case of Breckenridge-type hyperlipoproteinemia, with special reference to the genetic aspect of this new inherited disorder.

\section{Case Report}

The patients, siblings, are a 13-year-old Japanese girl (H.T.) and a 15-year-old boy (K.T.) who were referred to our lipid clinic of Osaka University Hospital because of serum turbidity. They were born to a consanguineous marriage and their parents were first cousins (Fig. 1). The patients had never experienced abdominal pain or diarrhea. They both were usually in good health and asymptomatic. Physical examination revealed well developed children. Neither hepatosplenomegaly nor xanthomas were observed. The tonsils were slightly enlarged but not pathological. The results of the laboratory examination are summarized in Table 1. They were unremarkable with the exception of very high serum triglyceride levels and a slightly elevated ASLO. Liver function tests and serum protein electrophoresis were normal. Fasting blood sugar was in the normal range and oral GTT revealed normal insulin and glucose responses. There was no sign of thyroid dysfunction. Serum triglyceride concentrations in H.T. and K.T. were $1094 \mathrm{mg} / \mathrm{dl}$ and $1090 \mathrm{mg} / \mathrm{dl}$, and cholesterol $161 \mathrm{mg} / \mathrm{dl}$ and 204 $\mathrm{mg} / \mathrm{dl}$, respectively, on a mild fat-restricted diet. Family screening was carried

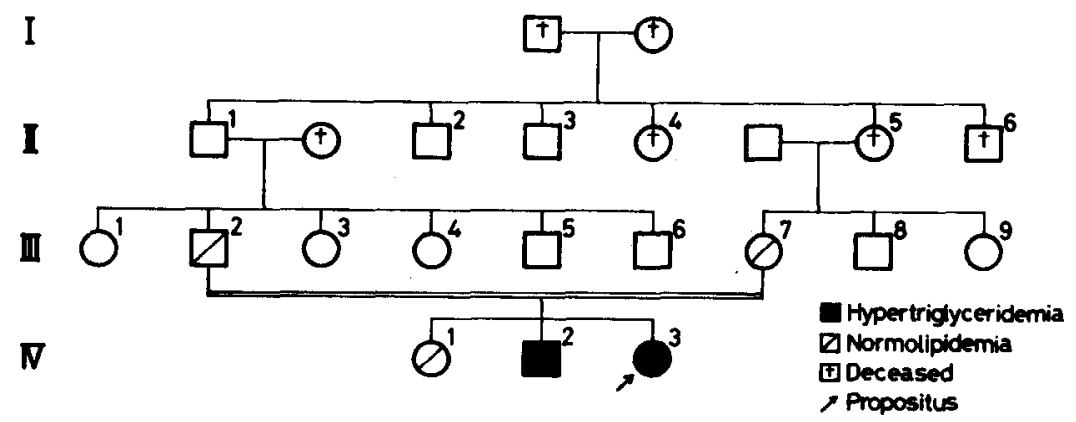

Fig. 1. T kindred, family tree. 
TABLE 1

LABORATORY MEASUREMENTS OF H.T. AND K.T.

\begin{tabular}{|c|c|c|c|c|}
\hline & \multicolumn{2}{|c|}{ H.T. } & \multicolumn{2}{|c|}{ K.T. } \\
\hline \multicolumn{5}{|l|}{ Urinalysis } \\
\hline Protein & \multicolumn{2}{|c|}{$(-)$} & \multicolumn{2}{|c|}{$(-)$} \\
\hline Sugar & \multicolumn{2}{|c|}{$(-)$} & \multicolumn{2}{|c|}{$(-)$} \\
\hline \multicolumn{5}{|l|}{ Blood analysis } \\
\hline $\mathrm{RBC}\left(\times 10^{4} / \mathrm{mm}^{3}\right)$ & \multicolumn{2}{|c|}{504} & \multicolumn{2}{|c|}{476} \\
\hline $\mathrm{Hb}(\mathrm{g} / \mathrm{dl})$ & \multirow{2}{*}{\multicolumn{2}{|c|}{$\begin{array}{l}14.6 \\
40.2\end{array}$}} & \multicolumn{2}{|c|}{13.6} \\
\hline $\mathrm{Ht}(\%)$ & & & & \\
\hline WBC $\left(/ \mathrm{mm}^{3}\right)$ & \multicolumn{2}{|c|}{$\begin{array}{l}40.2 \\
5200\end{array}$} & \multicolumn{2}{|c|}{4100} \\
\hline \multicolumn{5}{|l|}{ Serum chemistry } \\
\hline $\mathrm{Na}(\mu \mathrm{Eq} / \mathbf{1})$ & \multicolumn{2}{|c|}{137} & \multicolumn{2}{|c|}{137} \\
\hline $\mathrm{K}(\mu \mathrm{Eq} / \mathrm{A})$ & \multicolumn{2}{|c|}{4.6} & \multicolumn{2}{|c|}{4.7} \\
\hline $\operatorname{Cl}(\mu \mathbf{E q} / \Lambda)$ & \multicolumn{2}{|c|}{96} & \multicolumn{2}{|c|}{98} \\
\hline Urea nitrogen $(\mathrm{mg} / \mathrm{dl})$ & \multicolumn{2}{|c|}{16.2} & \multicolumn{2}{|c|}{16.2} \\
\hline Uric acid $(\mathrm{mg} / \mathrm{dl})$ & \multicolumn{2}{|c|}{4.2} & \multicolumn{2}{|c|}{3.7} \\
\hline Amylase (Somogyi U) & \multicolumn{2}{|c|}{75} & & \\
\hline Total protein $(\mathrm{g} / \mathrm{d} \mathrm{l})$ & & & & \\
\hline Protein electrophoresis & & & & \\
\hline Albumin (\%) & & & & \\
\hline$\alpha_{1}$-Globulin $(\%)$ & & & & \\
\hline$\alpha_{2}$-Globulin (\%) & & & & \\
\hline$\beta$-Globulin (\%) & & & & \\
\hline$\gamma$-Globulin (\%) & & & & \\
\hline Cholesterol (mg/dl) & & & & \\
\hline Triglycerides (mg/d) & & & & \\
\hline ZTT (U) & & & & \\
\hline GOT (U) & & & & \\
\hline GPT (U) & & & & \\
\hline Alkaline phosphatase (K.A.U.) & & & & \\
\hline$\gamma$-GTP $(\mathrm{mU} / \mathrm{ml})$ & & & & \\
\hline$T_{4}(\mu \mathrm{g} / \mathrm{d} 1)$ & & & & \\
\hline Serological test & & & & \\
\hline $\mathrm{CRP}$ & & & & \\
\hline ASLO (T.U.) & & & & \\
\hline $\mathbf{R A}$ & & & & \\
\hline $0 . G T T(100 \mathrm{~g}$ glucose $)$ & BS a & IRI $b$ & BS $^{\mathbf{a}}$ & IRI $\mathbf{b}$ \\
\hline 0 (min) & 82 & 16 & 80 & 11 \\
\hline 30 & 119 & 41 & 119 & 24 \\
\hline 60 & 93 & 33 & 103 & 27 \\
\hline 90 & 93 & 20 & 98 & 15 \\
\hline 120 & 93 & 25 & 102 & 17 \\
\hline 180 & 62 & 11 & 89 & 6 \\
\hline
\end{tabular}

a Blood sugar (mg/dl); b immunoreactive insulin $(\mu \mathrm{U} / \mathrm{ml})$.

out for the parents and another sibling. The clinical and biochemical characteristics of the members of this family are listed in Table 2.

Materials and Methods

For preparative ultracentrifugation, blood samples were collected into EDT A-2Na $(1 \mathrm{mg} / \mathrm{ml})$ following an overnight fast. Plasma was separated promptly after low-speed centrifugation at room temperature and kept at $4^{\circ} \mathrm{C}$ 


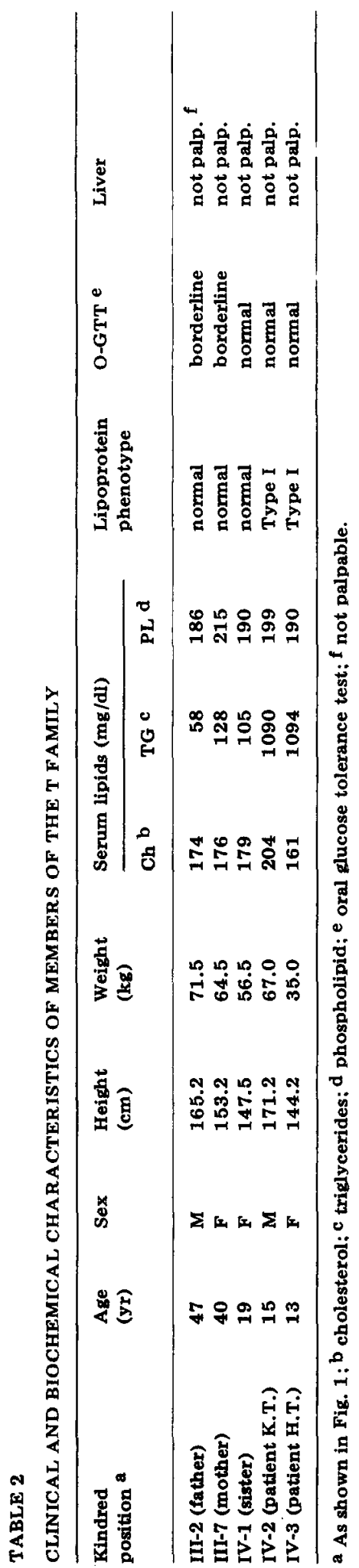


until analysis. Other studies were performed on blood serum unless otherwise indicated.

Lipids were extracted with chloroform-methanol according to the method of Folch et al. [11]. Cholesterol was determined by the method of Zurkowski [12] and phospholipid was obtained by a modification of the method of Cahn et al. [13]. Triglycerides were determined by periodate oxidation and reaction with acetylacetone following treatment of the serum with Zeolite [14]. The amount of total apoproteins in the lipoprotein fractions was determined by the method of Lowry et al. [15], using crystalline bovine serum albumin as a standard. Reaction mixtures were extracted twice with chloroform after color development.

The plasma lipoproteins were analyzed using a combination system of polyacrylamide gel electrophoresis (PAGE), preparative ultracentrifugation and heparin-manganase precipitation. PAGE was performed on Sudan Black B-prestained serum samples using a 3.0\% running gel for lipoprotein separation by the method of Narayan et al. [16]. Lipoprotein patterns were obtained by densitometric scanning with a densitometer (Fuji FD-A-IV).

Quantitative ultracentrifugation was carried out in a Hitachi model 55P-7 ultracentrifuge using a RP-40 rotor head according to the method of Hatch and Lee [17]. Plasma samples were centrifuged at $25,000 \mathrm{rpm}$ for $25 \mathrm{~min}$ in order to separate chylomicrons. Very low density lipoprotein (VLDL, $d<1.006$ ) was isolated in the top fraction from chylomicron-free plasma after $18 \mathrm{~h}$ of ultracentrifugation at $40,000 \mathrm{rpm}$ in a solvent with a density of 1.006 . The heparinmanganase precipitation method [18] was used to precipitate low density lipoprotein (LDL) from the bottom fraction $(d>1.006)$ of the last ultracentrifugation and high density lipoprotein (HDL) was obtained as the supernatant. The concentrations of cholesterol and triglyceride were measured in each of these lipoprotein fractions.

Tetramethylurea (TMU)-soluble apolipoproteins in chylomicrons and VLDL were analyzed by PAGE according to the method of Kane [19] with a minor modification. Washed chylomicrons or VLDL preparations containing approximately $60-100 \mu \mathrm{g}$ of total protein were mixed with TMU. After delipidation, an aqueous solution of Bromophenol Blue (BPB) was added as an indicator to each preparation. Electrophoresis was carried out using a 7.5\% running gel containing $6 \mathrm{M}$ urea. Gels were stained by Amido Black 10B for $30 \mathrm{~min}$ and destained in $7 \%$ acetic acid solution followed by densitometer scanning. The relative concentration of apo C-II in VLDL was determined as the ratio of the scanned area of apo C-II peak to that of apo C-III peaks (C-III-1 plus C-III-2) in densitometric scanning of electrophoretograms of TMU-soluble apo-VLDL.

Apo C-II was isolated by the following procedures. TMU-soluble apo-VLDLs from patients with hypertriglyceridemia were separated by electrophoresis on large preparative polyacrylamide gels and visualized under ultraviolet light after staining with the magnesium salt of 8-anilino-1-naphthalene sulfonic acid in saturated $\left(\mathrm{NH}_{4}\right)_{2} \mathrm{SO}_{4}$ [20]. The fluorescent bands of apo C-II were cut out and extracted with water. The extract containing apo C-II was dialyzed and lyophilized.

Postheparin plasma was obtained at $10 \mathrm{~min}$ after intravenous injection of sodium heparin $(0.1 \mathrm{mg} / \mathrm{kg}$ body weight) after an overnight fast. Samples were 
collected into tubes containing $0.1 \mathrm{ml}$ of $0.1 \mathrm{M}$ sodium citrate per ml. The plasma was separated by low-speed centrifugation at $4^{\circ} \mathrm{C}$. Postheparin lipolytic activity (PHLA) was determined by the modified method of Okuda et al. [21]. The assay system consisted of $0.05 \mathrm{ml}$ of $1: 4$ diluted Ediol, $0.45 \mathrm{ml}$ of $0.1 \mathrm{M}$ Tris-HCl buffer $\mathrm{pH} 9.0$ containing $5 \%(\mathrm{w} / \mathrm{v})$ bovine serum albumin (Fraction $\mathrm{V}$ ) with or without $2 \mathrm{M} \mathrm{NaCl}$ (final concentration $0.9 \mathrm{M}$ ) and $0.5 \mathrm{ml}$ of diluted postheparin plasma. When serum or apo C-II was added to the assay mixture as an activator, $0.25 \mathrm{ml}$ of postheparin plasma and $0.25 \mathrm{ml}$ of serum or apo C-II in saline were used instead of diluted postheparin plasma. After incubation for $1 \mathrm{~h}$ at $37^{\circ} \mathrm{C}$, released free fatty acids (FFA) were extracted and titrated by the method of Dole [22]. The results were expressed as $\mu \mathrm{Eq}$ of released FFA $/ \mathrm{ml}$ of postheparin plasma/h. The activity obtained in high-salt buffer corresponded to the activity of H-TGL $[7,8]$. The activity of LPL was calculated by subtracting the value of H-TGL from the total activity obtained in low-salt conditions.

The ability of human serum to activate guinea pig lipoprotein lipase was measured according to the method of Chu et al. [23]. The guinea pig blood samples were withdrawn after $4 \mathrm{~min}$ following the intracardiac injection of sodium heparin $(20 \mathrm{U} / \mathrm{kg}$ body weight). Guinea pig postheparin plasma and human sera obtained from members of the $\mathrm{T}$ family and from healthy normolipidemic volunteers were stored at $-10^{\circ} \mathrm{C}$ until use. Lipolytic activity of guinea pig postheparin plasma showed a linear increase in proportion to the amount of standard human serum added to the assay mixture at least up to $0.6 \mathrm{ml}$. Accordingly, the assay was carried out after addition of $0.4 \mathrm{ml}$ of test serum. The activity was expressed arbitrarily as units percent of a standard serum after subtraction of basal lipolytic activity of guinea pig postheparin plasma.

\section{Results}

\section{Serum lipids, lipoproteins and apolipoproteins}

The serum lipid levels and the lipid composition of lipoproteins in members of the $T$ family are summarized in Tables 2 and 3 . In patients H.T. and K.T. serum triglyceride concentrations were very high, $1094 \mathrm{mg} / \mathrm{dl}$ and $1090 \mathrm{mg} / \mathrm{dl}$,

TABLE 3

LIPOPROTEIN LIPID CONCENTRATIONS IN THE PATIENTS AND THEIR PARENTS

\begin{tabular}{|c|c|c|c|c|c|c|c|c|c|}
\hline \multirow[t]{2}{*}{ Subject } & \multicolumn{5}{|c|}{ Cholesterol (mg/dl) } & \multicolumn{4}{|c|}{ Triglycerides (mg/dl) } \\
\hline & Total & Chylo. a & VLDL & LDL $\mathrm{c}$ & HDL $c$ & Total & Chylo. a & VLDL & LDL + HDL b \\
\hline Patient H.T. & 161 & 98 & 35 & 12 & 16 & 1094 & 813 & 219 & 62 \\
\hline Patient K.T. & 204 & 119 & 45 & $\mathbf{2 3}$ & 17 & 1090 & 823 & 198 & 69 \\
\hline Father & 174 & - & 2 & 129 & 43 & $\mathbf{5 8}$ & - & 10 & 48 \\
\hline Mother & 176 & - & 21 & 105 & 50 & 128 & - & 67 & 61 \\
\hline
\end{tabular}

a Chylomicrons.

b Bottom fractions isolated by ultracentrifugation at $d=\mathbf{1 . 0 0 6}$ from chylomicron-free plasma.

c Isolated by heparin-manganese precipitation method from ultracentrifugal bottom fraction at $d=1.006$. 
respectively, but serum cholesterol levels were within the normal range, 161 $\mathrm{mg} / \mathrm{dl}$ and $204 \mathrm{mg} / \mathrm{dl}$, on a mild fat-restricted diet. The lipoprotein pattern on PAGE revealed a high chylomicron peak in each patient but normal patterns were obtained from other relatives (Fig. 2). By ultracentrifugal analysis, more than $80 \%$ of plasma triglycerides were recovered in the chylomicron fraction from each patient. The amount of cholesterol in this fraction was $98 \mathrm{mg} / \mathrm{dl}$ in H.T. and $119 \mathrm{mg} / \mathrm{dl}$ in K.T., corresponding to more than half the value for total plasma cholesterol. However, HDL- and LDL-cholesterol were markedly reduced, $12 \mathrm{mg} / \mathrm{dl}$ and $16 \mathrm{mg} / \mathrm{dl}$ in H.T., and $23 \mathrm{mg} / \mathrm{dl}$ and $17 \mathrm{mg} / \mathrm{dl}$ in K.T., respectively. In contrast, the parents and an elder sister had completely normal serum lipid and lipoprotein levels.

The densitometric pattern of apolipoproteins in the chylomicron fractions is shown in Fig. 3. The C apoproteins are clearly separated into C-I, C-II, C-III-1 and C-III-2 on PAGE [19], as shown in the control. In our PAGE system, the Rf values for apo C-II, apo C-III-1 and apo C-III-2 (with BPB band as a reference) were $0.52-0.54,0.60-0.62$ and $0.66-0.68$, respectively. In contrast to the control, apo C-II band was not detected in chylomicron apoproteins obtained from patient K.T. (Fig. 3). The same result, not shown in the figure, was obtained for VLDL apoprotein in this patient. The lack of apo C-II on PAGE was also observed in triglyceride-rich lipoproteins from patient H.T. On the other hand, the apo C-II band was clearly observed on PAGE of apo-VLDL in their parents. However, the relative concentration of their apo C-II was reduced, approximately $50 \%$ of the mean control value (Table 4 ).
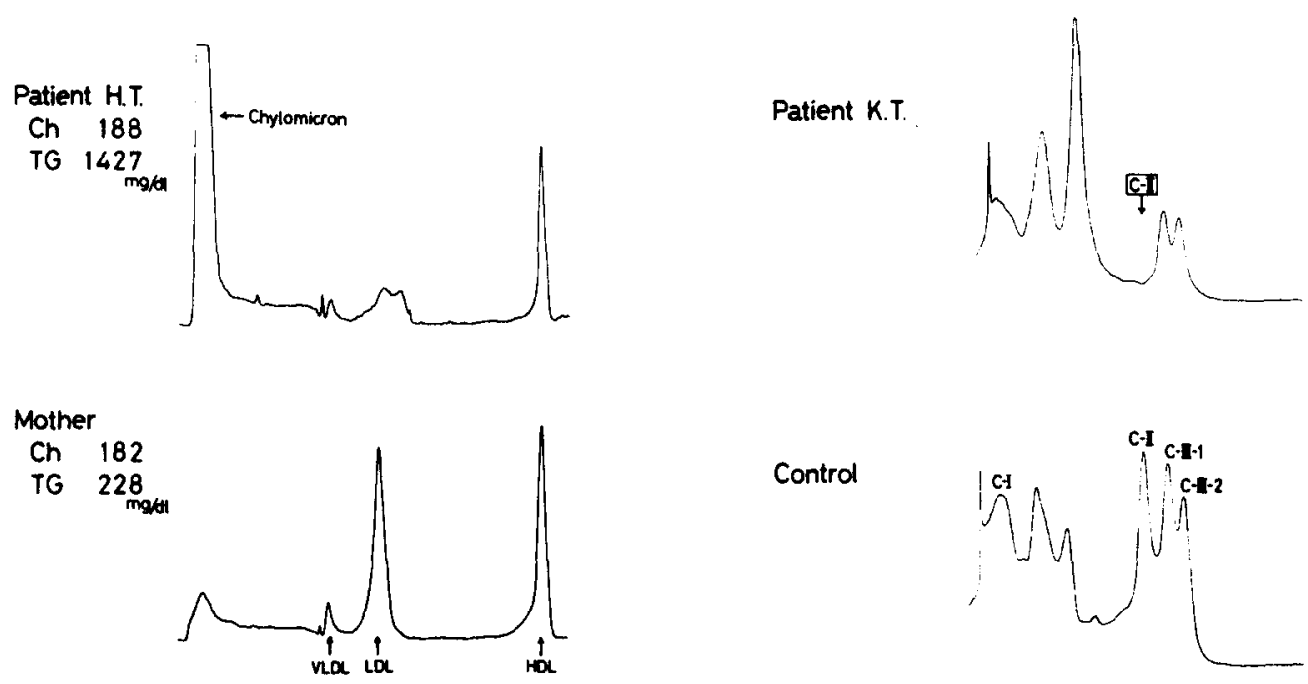

Patient K.T.

Fig. 2. Densitometric patterns of polyacrylamide gel electrophoresis of serum lipoproteins in patient H.T. (upper) and her mother (lower). The pattern in patient K.T. was similar to that in H.T., and patients' father and sister, to that in their mother.

Fig. 3. Densitometric patterns of polyacrylamide gel electrophoresis of TMU-soluble apoproteins in chylomicrons trom patient K.T. (upper) and from a contxol subject with hyperchylomicronemia previously clanified as LPL deficiency (lower). C-II] (upper panel) indicates the position of apoprotein C-II peak, if present, judged by the $R f$ value. 
TABLE 4

RELATIVE CONCENTRATION OF APOLIPOPROTEIN C-II IN VLDL FROM MEMBERS OF THE T FAMILY AND CONTROL SUBJECTS

\begin{tabular}{llc}
\hline Subject & Ratio of $\frac{\text { Apo C-II a }}{\text { Apo-C-III }}$ & \% of control value \\
\hline Patient H.T. & 0 & 0 \\
Patient K.T. & 0 & 0 \\
Father & 0.19 & 48 \\
Mother & 0.17 & 43 \\
Controls & $0.40 \pm 0.10 \mathrm{~b}$ & 100 \\
\hline
\end{tabular}

a Calculated from areas of densitometric peaks. See text.

b Mean \pm SD for 5 normolipidemic healthy subjects.

\section{Postheparin lipolytic activity}

As familial type I hyperlipoproteinemia was strongly suggested in these patients by the lipid and lipoprotein analyses, LPL and H-TGL activities were measured using selective $\mathrm{NaCl}$ inactivation in the postheparin plasma. In both patients (H.T. and K.T.) LPL activities were markedly decreased. Furthermore, H-TGL activities were also significantly lower than normal (Fig. 4). Their parents and elder sister, however, had normal LPL with subnormal or normal H-TGL activities (Fig. 4). When the serum from normolipidemic subjects was added to the assay mixture for PHLA, as shown in Methods, LPL activity markedly increased into or above the normal range (Fig. 5). H-TGL was not activated by normal serum. Activation of LPL by human serum was not observed in their parents and other hyperlipidemic subjects. When purified apo C-II $(15 \mu \mathrm{g})$ was added to the assay mixture in place of whole serum, LPL activity increased approximately to the same extent (Fig. 5).



Fig. 4. Postheparin lipolytic activity and serum lipid concentrations in patients and their relatives. Each assay was performed as described in Methods. Both patients were examined before (H.T. -1 and $K . T$. -1 ) and after (H.T. -2 and K.T. -2) a low-fat diet. Serum lipid concentrations were measured in blood samples obtained before heparin injection. Shaded areas represent the normal range (mean $\pm \mathrm{SD}$ ). 


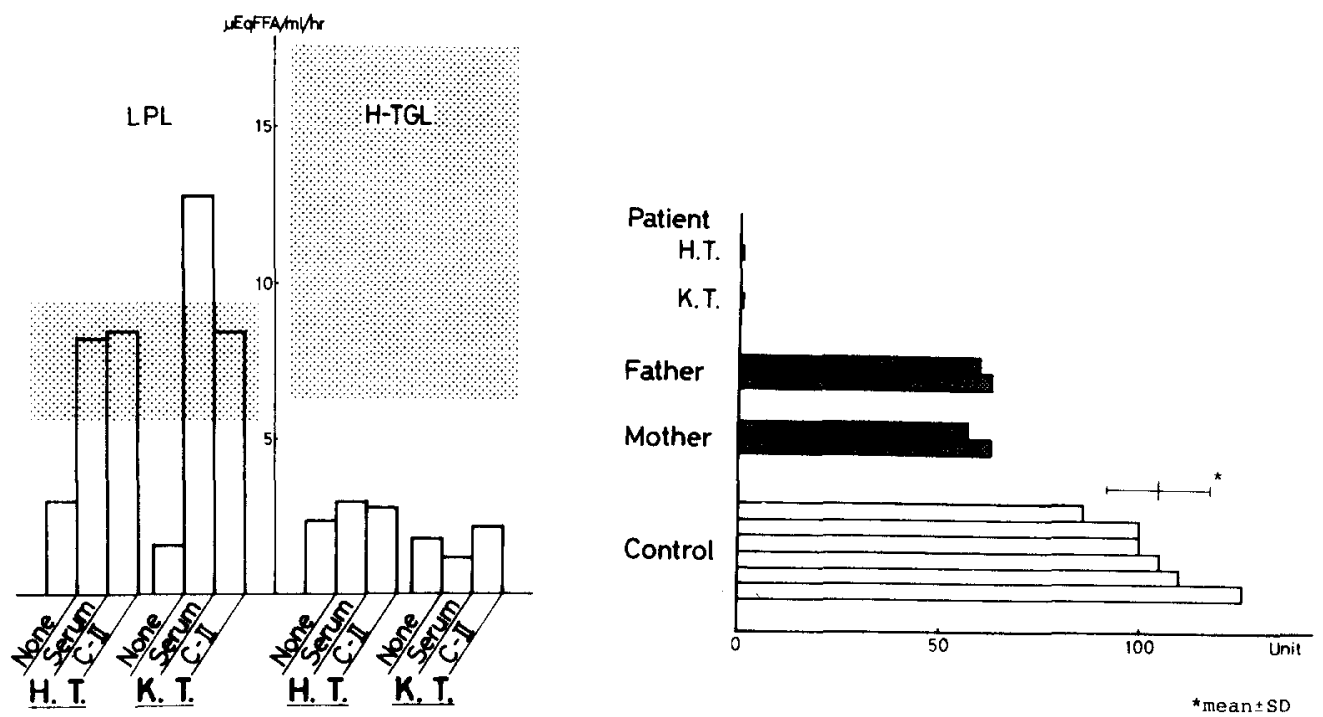

Fig. 5. Lipoprotein lipase and hepatic triglyceride lipase activities in postheparin plasma from patients estimated after the addition of normal serum or purified apo C-II to the assay mixture. $0.25 \mathrm{ml}$ of serum from a numolipidemic subject or $15 \mu \mathrm{g}$ of apo $C$-II were added lo the assay mixlure. Experiments were carried out as shown in the text. Shaded areas represent the normal range (mean $\pm \mathrm{SD}$ ).

Fig. 6. The levels of lipase activator in the serum of patients and their parents. Results are expressed in arbitrary units percent of the value obtained for a standard serum after subtraction of basal lipolytic activity of guinea pig postheparin plasma. Assay was performed twice in the same serum samples against different guinea pig postheparin plasma in the parents. Control subjects are six healthy volunteers without hyperlipoproteinemia.

\section{The LPL activator assay}

Since there is no activator for LPL in guinea pig postheparin plasma [24], triglycerides cannot be hydrolyzed unless rat or human serum is added $[25,26]$. The activating ability of sera from patients and their parents was determined as lipolytic activity when a constant volume $(0.4 \mathrm{ml})$ of test serum was added to the assay system. In contrast to the healthy control, serum from the patients (H.T. or K.T.) did not activate guinea pig LPL, as shown in Fig. 6. Furthermore, serum from the parents showed approximately only $60 \%$ of the control activation ability value, $105 \pm 13 \mathrm{U}$ (Fig. 6).

\section{Discussion}

Our patients (H.T. and K.T.) had once been thought to have familial type I hyperlipoproteinemia (familial LPL deficiency), because they have heavy chylomicronemia and an apparent deficiency of LPL shown by routine PHLA activity. Hyperlipoproteinemia secondary to systemic lupus erythematosus, diabetes mellitus, hypothyroidism or paraproteinemia, was ruled out by physical and laboratory examinations. Apoprotein analysis of triglyceride-rich lipoproteins demonstrated the lack of apo C-II in both our patients, whereas apo C-II is one of the major apoproteins in triglyceride-rich lipoproteins from normal subjects. Apo C-II has been detected in those other cases of type I 
hyperlipoproteinemia with LPL deficiency (Fig. 3). The functional role of the various apolipoproteins has not until now been completely understood. However, it is well known that apo C-II is an important activator for LPL [3-6]. Although a marked reduction in LPL activity was observed by the standard assay procedure of PHLA, where postheparin plasma is used as an enzyme source as well as a sole source of the activator, activity completely recovered after addition of normal serum or purified apo C-II.

These observations indicate that the patients H.T. and K.T. are not really deficient in LPL and that the cause of their chylomicronemia is a deficiency in its activator. On the other hand, patients with typical type I hyperlipoproteinemia show a real deficiency of LPL in postheparin plasma [9] as well as in adipose tissue [27]. This means that LPL activity cannot further increase after addition of normal serum or apo C-II $[9,28]$. Chylomicron triglycerides in our patients with familial apo C-II deficiency were not hydrolyzed by LPL - inactivated by the lack of an activator - so that the chylomicronemia appeared the same as in the classical type of familial LPL deficiency.

The analysis of apoproteins in HDL was not performed in this study. However, based upon the observation that the serum from the patients failed to activate LPL in guinea pig postheparin plasma (Fig. 6), it can easily be presumed that the same deficiency of apo C-II is present in HDL as in chylomicrons and VLDL, because the $\mathrm{C}$ apolipoproteins are interchangeable between triglyceride-rich lipoproteins and HDL in the process of lipoprotein metabolism โ29].

Recently Breckenridge et al. [10] have described a 59-year-old male with severe hypertriglyceridemia caused by the absence of apo C-II and suggested his disease be called apolipoprotein C-II deficiency. Our patients have a hyperlipoproteinemia with a biochemical defect similar to Breckenridge's patient. But our patients have never suffered from xanthomas, pancreatitis or diabetes mellitus. The presence of diabetes mellitus, which is not a common complication of familial LPL deficiency, must have aggravated the clinical features of the case of Breckenridge et al. Serum triglyceride concentrations in our patients were usually less than $2500 \mathrm{mg} / \mathrm{dl}$, and relatively lower than the value of Breckenridge's patient or of subjects with typical familial LPL deficiency reported by American and European authors. The regular diet in Japan is comparatively low in fat and calories compared with that in Western countries and it is, therefore, suggested that pancreatitis and xanthomas did not develop in our patients because of the relatively low serum triglyceride levels. Youth may also have been a contributory factor.

Most cases of reported familial LPL deficiency have normal H-TGL activity in postheparin plasma [9]. However, moderately reduced H-TGL activities were obtained for both our patients, in agreement with the data for the first patient with apo C-II deficiency. Reduced H-TGL activity is frequently observed in subjects with hypertriglyceridemia [30]. The physiological role of H-TGL is at present not well known. As the recovery of H-TGL activity was obtained in patient H.T. following reduced serum triglyceride concentration on a low-fat diet (Fig. 4), the decrease in H-TGL seems to be a secondary phenomenon. Furthermore, there is a possibility that abnormal H-TGL or inhibitors of H-TGL may have been present in the patients' postheparin plasma, for 
example, an inactive form of LPL in the absence of apo C-II. Ganesan et al. [31] described another LPL $\left(\mathrm{LPL}_{\mathrm{C}-1}\right)$ in human postheparin plasma which requires apo C-I as an activator instead of apo C-II, and showed that $L \mathrm{~L}_{\mathrm{C}-\mathrm{I}}$ activity was absent in postheparin plasma from type I hyperlipoproteinemia. In our patients' sera the band corresponding to apo C-I was detected on PAGE (Fig. 4), although the assay of $L P L_{C-I}$ was not performed in this study.

The parents had normal lipid concentrations and are first cousins. Two of their three children (one of each sex) have been affected with hyperchylomicronemia. Thus, it is strongly suggested that the disorder is inherited as an autosomal recessive mode. It is reasonable to presume that some members of the kindred, including the parents of the patients, must have carried a single mutant allele to become heterozygotes. The consanguineous marriage of heterozygotes could give rise to the birth of homozygotes (patients H.T. and K.T.) bearing two mutant alleles.

The LPL activator assay carried out in this study is thought to indicate only the net LPL activating power of the serum and not the exact amount of apo C-II itself, because apo $C$-III $[5,32]$ and apo $E[33,34]$ which reportedly inhibit LPL are also present in the same serum. Nevertheless, assuming that the level of I.PI, activating power obtained here correlates with the apo C-II level in serum, it can be postulated that apo C-II levels in the parents' sera were reduced to approximately half the mean control value (Fig. 6); this strongly suggests that the parents were heterozygotes. This consideration is also supported by the relative concentration of apo C-II in VLDL (Table 4).

The parents were normolipidemic and had almost normal LPL activity in postheparin plasma, which was not increased by the addition of normal serum. These results indicate that the heterozygote for familial apo C-II deficiency has a decreased apo C-II level in his plasma but the amount is enough to activate LPL for hydrolysis of chylomicrons, while the homozygote with no detectable apo C-II suffers from hyperchylomicronemia. Our view of the heterozygote is supported by the observation of Breckenridge et al. that the plasma triglyceride level fell dramatically in a patient with apo C-II deficiency when the apo C-II concentration in his VLDL reached only $5-10 \%$ of its normal value after infusion of normal plasma [10].

\section{Addendum}

After this manuscript was completed, Cox et al. [35] reported that apo C-II deficiency is inherited as an autosomal recessive trait. This conclusion was based on a study of the relatives of Breckenridge's patient with apo C-II deficiency. Seven homozygotes and ten heterozygotes for the disease were found in the same kindred. Our observations concerning inheritance of the disease agrees well with Cox et al.

\section{References}

1 Fredrickson, D.S., Goldstein, J.L. and Brown. M.S.. The familial hyperlipoproteinemias, In: J.B. Stanbury, J.B. Wyngaarden and D.S. Fredrickson (Eds.), The Metabolic Basis of Inherited Disease. 4th edition, McGraw-Hill, New York, N.Y., 1978, p. 604. 
2 Havel, R.J, and Gordon, R.S., Jr., Idiopathic hyperlipemia, Metabolic studies in an affected family, J. Clin. Invest., 39 (1960) 1777.

3 Havel, R.J., Shore, V.G., Shore, B. and Bier, D.M., Role of specific glycopeptides of human serum lipoproteins in the activation of lipoprotein lipase, Circ. Res., 27 (1970) 595.

4 LaRosa, J.C., Levy, R.I., Herbert, P., Lux, S.E. and Fredrickson, D.S., A specific apoprotein activator for lipoprotein lipase, Biochem. Biophys. Res. Commun., 41 (1970) 57.

5 Ganesan, D., Bradford, R.H., Alaupovic, P. and McConathy, W.J., Differential activation of lipoprotein lipase from human post-heparin plasma, milk and adipose tissue by polypeptides of human serum apolipoprotein C, FEBS Letters, 15 (1971) 205.

6 Havel, R.J., Fielding, C.J., Olivecrona, T., Shore, V.G., Fielding, P.E. and Egelrud, T., Cofactor activity of protein components of human very low density lipoproteins in the hydrolysis of triglycerides by lipoprotein lipase from different sources, Biochemistry, 12 (1973) 1828.

7 LaRosa, J.C., Levy, R.I., Windmueller, H.G, and Fredrickson, D.S., Comparison of the triglyceride lipase of liver, adipose tissue, and postheparin plasma, J. Lipid Res., 13 (1972) 356.

8 Krauss, R.M., Windmueller, H.G., Levy, R.I. and Fredrickson, D.S., Selective measurement of two different triglyceride lipase activities in rat postheparin plasma, J. Lipid Res., 14 (1973) 286.

9 Krauss, R.M., Levy, R.I. and Fredrickson, D.S., Selective measurement of two lipase activities in postheparin plasma from normal subjects and patients with hyperlipoproteinemia. J. Clin. Invest.. 54 (1974) 1107.

10 Breckenridge, W.C., Little, J.A., Steiner, G., Chow, A. and Poapst, M., Hypertriglyceridemia associated with deficiency of apolipoprotein C-II, New Engl. J. Med., 298 (1978) 1265.

11 Folch, J., Lees, M. and Sloane Stanley, G.H., A simple method for the isolation and purification of total lipides from animal tissues, J. Biol. Chem., 226 (1957) 497.

12 Zurkowski, P., A rapid method for cholesterol determination with a single reagent, Clin. Chem., 10 (1964) 451 .

13 Cahn, P.S., Jr., Toribara, T.Y. and Warner, H., Microdetermination of phosphorus, Anal. Chem., 28 (1956) 1756.

14 Fletcher, M.J., A colorimetric method for estimating serum triglycerides, Clin. Chim. Acta, 22 (1968) 393.

15 Lowry, O.H., Rosebrough, N.J., Farr, A.L. and Randall, R.J., Protein measurement with the Folin phenol reagent, J. Biol. Chem., 193 (1951) 265.

16 Narayan, K.A., Creinin, H.L. and Kummerow, F.A., Disc electrophoresis of rat plasma lipoproteins, J. Lipid Res., 7 (1966) 150.

17 Hatch, F.T. and Lees, R.S., Practical methods for plasma lipoprotein analysis, Adv. Lipid Res., 6 (1968) 1 .

18 Burstein, M. and Scholnick, H.R., Lipoprotein-polyanion-metal interactions, Adv. Lipid Res., 11 (1973) 68 .

19 Kane, J.P., A rapid electrophoretic technique for identification of subunit species of apoproteins in serum lipoproteins, Anal. Biochem., 53 (1973) 350.

20 Nerenberg, S.T., Ganger, C. and DeMarco, L., Kapid fluorescent "staining" of nondenatured protein bands in agar and polyacrylamide gels, Anal. Biochem., 43 (1971) 564.

21 Ikeda, Y., Okamura, K., Arima, T. and Fujil, S., Purification and characterization of two types of esterase from rat liver microsomes, Biochim. Biophys. Acta, 487 (1977) 189.

22 Dole, V.P., A relation between non-esterified fatty acids in plasma and the metabolism of glucose, J. Clin. Invest., 35 (1956) 150.

23 Chu, P., Miller, A.L. and Mills, G.L., Assay of an activator for lipiprotein lipase, Clin. Chim. Acta, 66 (1976) 281.

24 Chapman, M.J., Mills, G.L. and Ledford, J.H., The distribution and partial chatacterization of the serum apolipoproteins in the guinea pig. Biochem. J., 149 (1975) 423.

25 Whayne, T.F., Jr. and Felts, J.M., Activation of lipoprotein lipase, Comparative study of man and other mammals, Circ. Res., 26 (1970) 545.

26 Bier, M.D. and Havel, R.J., Activation of lipoprotein lipase by lipoprotein fractions of human serum. J. Lipid Res., 11 (1970) 565.

27 Harlan. W.R., Jr., Winesett, P.S. and Wasserman, A.J., Tissue lipoprotein lipase in normal individuals and in individuals with exogenous hypertriglyceridemia and the relationship of this enzyme to assimilation of fat. J. Clin. Invest., 46 (1967) 239.

28 Sudo, H. and Yamamura, T., Unpublished data.

29 Havel, R.J., Kane, J.P. and Kashyap, M.L., Interchange of apolipoproteins between chylomicrons and high density lipoproteins during alimentary lipemia in man, J. Clin. Invest., 52 (1973) 32.

30 Yamamura, T., Sudo, H., Matsuzawa, Y. and Yamamoto, A., Familial hyperlipoproteinemia showing an interconversion between types III and $V$ linked with a trait of xeroderma pigmentosum, Med. J. Osaka Univ., In press.

31 Ganesan, D., Bradford, R.H., Ganesan, G., McConathy, W.J., Alaupovic, P. and Bass, H.B., Purified postheparin plasma lipoprotein lipase in primary hyperlipoproteinemias, J. Appl. Physiol., 39 (1975) 1022. 
32 Brown, W.V. and Baginsky, M.L., Inhibition of lipoprotein lipase by an apoprotein of human very low density lipoprotein, Biochem. Biophys. Res. Commun., 46 (1972) 375.

33 Ekman, R. and Nilsson-Ehle, P., Effects of apolipoproteins on lipoprotein lipase activity of human adipose tissue, Clin. Chim. Acta, 63 (1975) 29.

34 Ganesan, D., Bass, H.B., McConathy, W.J. and Alaupovic, P., Is decreased activity of C-II activated lipoprotein lipase in type III hyperlipoproteinemia (broad- $\beta$-disease) a cause or an effect of increased apolipoprotein E levels?, Metabolism, 25 (1976) 1189.

35 Cox, D.W., Breckenridge, W.C. and Little, J.A., Inheritance of apolipoprotein C-II deficiency with hypertriglyceridemia and pancreatitis, New Engl. J. Med., 229 (1978) 1421. 